and a final paper on preparation and properties of spinel. There are five papers dealing with properties. Three concern electrical properties. Under electrical stress, especially at elevated temperatures, ions from electrodes and from the ceramic material itself migrate, causing rapid degradation of electrical characteristics. This important commercial topic is dealt with at length. The other two papers are concerned with thermal conductivity and friction characteristics of some special compounds. Of the three fabrication papers, two discuss hot-pressing techniques, and the third electron beam melting. In two papers on applications, emphasis is placed on the use of ceramics in high-performance gas. turbine and jet engines.

Most of the papers are short and the inclusion of numorous photographs, figures, graphs and good abstracts makes for easy reading. The British Ceramic Research Association is to be congratulated for producing this useful book, and for playing their full part in leading ceramies out of the empirical wilderness.

J. H. Manning

\section{CHEMISTRY OF NATURAL PRODUCTS}

\section{Recent Developments in the Chemistry of Natural Carbon Compounds}

Vol. 1. Edited by R. Bognár, V. Bruckner and G. Fodor. Pp. 319. (Budapest: Akadémiai Kiadó, Publishing House of the Hungarian Academy of Sciences, 1965.) 14.70 dollars.

HE Chemical Department of the Hungarian Academy of Sciences has set itself the task of publishing a series of monographs on natural products, dealing mainly with the elucidation of structures. It is claimed as an individual feature of the series that it will collect for the first time relevant work of Hungarian chemists and offer to the English-speaking reader material that may only have been accessible previously with difficulty.

Recent Developments in the Chemistry of Natural Carbon Compounds, the first volume in the series, comprises three monographs by distinguished authors. About half the book (146 pp.) is taken up by a very detailed, lively and critical review by G. Fodor entitled "New Methods and Recent Developments of the Stereochemistry of Ephedrine, Pyrrolizidine, Granatane and Tropane Alkaloids". The major part of this monograph concerns, of course, the tropane alkaloids which have been so thoroughly investigated by Fodor and his collaborators, who have published much of their work in the Journal of the Chemical Society. The second monograph (70 pp.), entitled "Relationships between the Structure and Pharmacological Activity of Tropeines", by K. Nádor, continues the alkaloidal theme and is complementary in a sense to that of Focior. It discusses parasympatholytic, ganglion-blocking, and local anaesthetic activities of tropeines, and the curare activity of bis-quaternary tropeines; biological activities relative to those of stand. ard compounds are given in convenient tabular form. The third monograph (85 pp.) entitled "Achievements in the Total Synthesis of Natural Steroids", by the Russian author, I. V. Torgov, is a more general and objective review of the methods that have been developed for the total synthesis of steroids. All the important routes are discussed in logical order, but, as there have been no Hungarian contributions to this field which is already well known to English-speaking readers, the reason for the inclusion of this admirably succinct contribution in the present volume is not clear.

The book is well produced and the standard of the English is quite high, but it suffers from two defects. In the first place, though published as recently as 1965 , the three monographs would appear to have been written about 1960 and such references as are given to later work appear as footnotes. Secondly, the analytical contents list at the beginning of the book is scarcely adequate to serve as an index to the very considerable amount of factual information contained between its covers. In spite of these minor shortcomings the book can be recommended for stimulating accounts of the three selected topics.

J. WALKER

\section{VALENCE THEORY}

Valence Theory

By Prof. J. N. Murrell, S. F. A. Kettle and Prof. J. M. Tedder. Pp. xiii +401. (London and Now York: John Wiley and Sons, 1965.) $50 s$.

URING the past thirty years, many, many books have been written on the subject of valence theory and its quantum mechanical basis. Some set out to explain the basic theoretical methods and to show how wave functions may be determined and used. Others aim to give a qualitative picture of the results of quantum mechanics as applied to molecular structure and to consider the application of these to a wide range of actual molecular examples. Because of the dangers of falling between two stools, it is particularly essential in this field for an author or authors to have a clear idea of who they are writing for. There are so many alternative approaches and needs that to attempt all may easily be to achieve nothing.

One great difficulty is, of course, that there are many chemists who need to have as good a grasp as possible of the ideas and results of quantum mechanics but who, because of the many other things they must learn, have only limited, and usually it must be accepted rathor inadequate, time to devote to it. Different teachers of valence theory would take different views as to how much it is reasonable to expect such experimental chemists to assimilate and how best to avoid the dangers of partial knowledge and limited understanding, but none, I think, would deny the greatness of the problem.

Murrell, Kettle and Tedder have in fact set themselves the very difficult task of trying to bridge the gap between the two types of approach as illustrated by those excellent books Valence, by C. A. Coulson, in which the approach is semi-qualitative, and Eyring, Walter and Kimball's more formal Quantum Chemistry. They have produced a book which will be valuable to experimental and semitheoretical chemists, whether they are interested in inorganic or in organic chemistry. There is a short introductory section dealing with such topics as the hydrogen atom and basio principles of valence theory. There follow a few chapters dealing with the mathematical foundation, symmetry and angular momentum. By this stage we are about one-third of the way through the book. Next there come chapters dealing with molecular orbital and valence bond theory, first in diatomic and then in polyatomic molecules. More specialized chapters follow which are devoted to ligand field theory, electron-deficient molecules, $\pi$-electron theory, induction, hyperconjugation, reactions in organic chemistry and weak chemical bonds. Valence Theory is written to be used by university students, and problems are included throughout; useful hints on their solution are given at the end of the book together with answers.

The material is presented clearly and the printing of formulae, tables and diagrams is of a high standard. The only worry $I$ have is that, in attempting to 'fill in the gap', the authors have at times involved themselves in fairly sudden changes in the difficulty of the material presented. For example, there are many who will find the change from the chapter entitled "Basic Principles" to the one entitled "Mathematical Foundations" quite 